\title{
Glucocorticoid signalling affects pancreatic development through both direct and indirect effects
}

\author{
E. Gesina • B. Blondeau • A. Milet • I. Le Nin • \\ B. Duchene $\cdot$ P. Czernichow $\cdot$ R. Scharfmann $\cdot$ \\ F. Tronche $\cdot$ B. Breant
}

Received: 19 April 2006 / Accepted: 4 August 2006 / Published online: 26 September 2006

(C) Springer-Verlag 2006

\begin{abstract}
Aims/hypothesis Beta cell development is sensitive to glucocorticoid levels. Although direct effects of glucocorticoids on pancreatic precursors have been shown to control beta cell mass expansion, indirect effects of these hormones on pancreatic development remain unexplored. This issue was addressed in mice lacking the glucocorticoid receptor (GR) in the whole organism.

Materials and Methods The pancreatic phenotype of $\mathrm{GR}^{\text {null/null }}$ mice was studied at fetal ages (embryonic day [E]) E15.5 and E18 by immunohistochemistry and beta cell fraction measurements. To distinguish between direct and
\end{abstract}

E. Gesina $\cdot$ B. Blondeau $\cdot$ B. Duchene $\cdot$ P. Czernichow $\cdot$ B. Breant INSERM U690, Hospital Robert Debré,

75019 Paris, France

B. Blondeau $\cdot$ B. Breant $(\square)$

INSERM U671, Cordeliers Biomedical Research Centre,

15 rue de l'Ecole de Médecine,

75270 Paris Cedex 06, France

e-mail: bernadette.breant@bhdc.jussieu.fr

B. Blondeau $\cdot$ B. Breant

UMRS 671, Cordeliers Biomedical Research Centre, IFR58,

University Pierre and Marie Curie,

75006 Paris, France

I. Le Nin $\cdot$ R. Scharfmann

INSERM E363, Hospital Necker,

René Descartes University Medical School,

75730 Paris Cedex 15, France

A. Milet $\cdot$ F. Tronche

Centre National de la Recherche Scientifique UMR7148,

Collège de France,

75231 Paris Cedex 05, France indirect effects, mutant E15.5 fetal pancreata were grafted under the kidney capsule of immunodeficient mice and analysed after 1 week.

Results E18 $\mathrm{GR}^{\text {null/null }}$ fetuses had smaller digestive tracts and tiny pancreata. Massive pancreatic disorganisation and apoptosis were observed despite the presence of all cell types. E15.5 $\mathrm{GR}^{\text {null/null }}$ mutants were indistinguishable from wild-type regarding pancreatic size, tissue structure and organisation, beta cell fraction and production of exocrine transcription factor Ptfla, neurogenin 3 and Pdx-1. Grafting E15.5 $\mathrm{GR}^{\text {null/null }}$ pancreata into a GR-expressing environment rescued the increased apoptosis and mature islets were observed, suggesting that $\mathrm{GR}^{\text {null/null }}$ pancreatic cell death can be attributed to indirect effects of glucocorticoids on this tissue. Heterozygous GR $^{+/ n u l l}$ mutants with reduced GR numbers showed no apoptosis but increased beta cell fraction at E18 and the adult age, strengthening the importance of an accurate GR dosage on beta cell mass expansion.

Conclusions/interpretation Our results provide evidence for GR involvement in pancreatic tissue organisation and survival through indirect effects. GR does not appear necessary for early phases, but its accurate dosage is critical to modulate beta cell mass expansion at later fetal stages, presumably through direct effects.

Keywords Development - Glucocorticoid receptor gene . Grafts $\cdot$ Mice $\cdot$ Pancreas
Abbreviations
BrdU 5-bromo-2'-deoxyuridine
GR glucocorticoid receptor
SCID severe combined immunodeficiency
TUNEL terminal transferase-mediated X-dUTP nick end labelling 


\section{Introduction}

Glucocorticoids are involved in various important physiological processes including immune responses and inflammation, carbohydrate, protein and lipid metabolism and cardiovascular function, as well as behavioural and neurobiological effects (for review see [1]). They may participate in the coordination of these processes since their circulating levels vary with a circadian rhythm and in response to stress. Glucocorticoids are synthesised in the adrenal cortex and secreted into the blood. Circulating levels of glucocorticoids are tightly regulated both through the hypothalamus-pituitary-adrenal axis [2] and locally in the target tissues, by the production of the $11 \beta$-hydroxysteroid dehydrogenase isoforms that control the balance between active and inactive steroids [3]. Glucocorticoids exert their effects by binding to the glucocorticoid receptor (GR), which is widely expressed [4-6], and in a few cell types by binding to the mineralocorticoid receptor [2]. Bound to its ligand, the GR is an active transcription factor that can both activate and inhibit the expression of target genes either after binding to DNA or through protein-protein interactions [6].

During the past decade, the possibility that fetal events may influence the risk of disease in adulthood has generated considerable interest. Individuals who were thin at birth are at increased risk of cardiovascular disease (including hypertension) and glucose intolerance or type 2 diabetes in adulthood [7-10]. From these epidemiological findings the concept of early programming of adult diseases arose. The mechanisms by which fetal undernutrition and/ or low birthweight increases the risk of developing these diseases are unclear. A dysfunction of stress response including increased circulating glucocorticoid levels is suspected in the aetiology of several metabolic disorders such as type 2 diabetes. In humans it is known that prenatal exposure to prednisone or maternal Cushing's syndrome is associated with intrauterine growth retardation (IUGR) [11, 12]. In rodents, fetal exposure to glucocorticoids induces IUGR at birth, and impaired glucose tolerance [13-15] and hypertension $[16,17]$ at adult age. Numerous studies have investigated the deleterious effects of glucocorticoids on pancreatic beta cell function, showing altered glucosestimulated insulin release, both in vitro in islets treated with dexamethasone [18-20] and in vivo in mice overexpressing GR in the beta cells $[21,22]$.

Few results are yet available on the effects of these hormones on their target tissues during development. However, such effects in early life could ultimately lead to metabolic diseases in adulthood. The analysis of mice in which the GR has been genetically modified, GR ${ }^{\text {hypo/hypo }}$ (also designated $\mathrm{GR}^{-/-}[6,23]$ and $\mathrm{GR}^{\text {nul//null }}[6,24,25]$ ), has provided evidence for a role of the GR in the development or function of several tissues, including fetal lung, adrenal and erythroblasts, and this modification is associated with neonatal death. We have previously shown that undernutrition during the last week of gestation in the rat increases both maternal and fetal glucocorticoid levels, which further causes decreased fetal pancreatic beta cell mass [26, 27]. In addition, in normally nourished rat fetuses increased beta cell mass was associated with low corticosterone levels, while decreased beta cell mass was observed under conditions of fetal overexposure to these hormones [28]. Beta cell development is thus sensitive to glucocorticoids. More precisely, the conditional inactivation of the GR in all pancreatic progenitors ( $\mathrm{GR}^{\mathrm{Pdx}-\mathrm{Cre}}$ mice) led to a doubling of beta cell mass [29].

In addition to direct effects, there may also be indirect effects of glucocorticoids in the aetiology of the metabolic syndrome. In the present work, we have explored whether impairing GR signalling in the whole organism similarly affects pancreatic development by studying the pancreatic phenotype of mouse fetuses carrying a deletion of exon 3 of the gene encoding GR, leading to a total absence of any GR protein carrying the DNA- or ligand-binding domains (GR ${ }^{\text {null/null }}$ mice). To decipher the role of GR in pancreatic and islet development we also studied the pancreatic phenotype of heterozygous $\mathrm{GR}^{+/ \text {null }}$ mutants at fetal and adult ages.

\section{Materials and methods}

Mouse breeding

$\mathrm{GR}^{\text {null/+ }}$ mice $[6,30]$ were on a $\mathrm{C} 57 \mathrm{BL} / 6$ and $129 \mathrm{Sve} / \mathrm{V}$ mixed genetic background. Animals were, however, backcrossed to C57BL/6 for five or six generations. Seven-weekold male severe combined immunodeficiency (SCID) mice (Charles River, L'Arbresle, France) were bred in isolators supplied with sterile-filtered, temperature-controlled air, as previously described [31]. The animals were housed with a 12-h light-dark cycle, and fed freely with a standard laboratory mouse chow (UAR A04; Villemoisson-sur-Orge, France).

\section{Dissection and genotyping}

The experiments on mice were carried out according to the 'Principles of laboratory animal care', National Institutes of Health (NIH) and French law (authorisation No. 7612 granted to B. Breant by the French Agricultural Ministry). Pregnant female mice were killed by decapitation and the fetuses were quickly removed from the uterine horns and placed on icecold PBS. All fetuses including the mutants were alive when taken out. Embryonic day (E) E15.5 as well as E18 entire digestive blocks were dissected under a microscope (Leica, 
Rueil-Malmaison, France) in PBS containing 0.37\% formalin to preserve tissue integrity. DNA extracted from the legs was used to genotype the fetuses by PCR, using primers GR12 (5'-CATGCTGCTAGGCAAATGATCTTAAC) and GR15 (5'-GAATGAGAATGGCCATGTACTAC) that amplify a 450-bp band for GR ${ }^{\text {null }}$ allele, and GR12 and GR30 (5'CTTCCACTGCTCTTTTAAAGAAGAC) that amplify a 280-bp fragment for the wild-type allele.

\section{Fixation and tissue processing}

The entire digestive blocks from E18 fetuses as well as pancreata from E15.5 fetuses and adult $\mathrm{GR}^{+/ \text {null }}$ and $\mathrm{GR}^{+/+}$ mice were fixed in $3.7 \%$ formalin solution, dehydrated and embedded in paraffin, as previously described [29]. Tissues were entirely cut into $6-\mu \mathrm{m}$-thick sections, transversally for the digestive blocks and sagittally for the pancreata. The sections were collected on poly-L-lysine-coated slides, left at $37^{\circ} \mathrm{C}$ overnight and stored at $4^{\circ} \mathrm{C}$ until processed for immunohistochemistry.

\section{Graft experiments}

Embryonic pancreata from three $\mathrm{GR}^{\text {null/null }}$ and three $\mathrm{GR}^{+/+}$ E15.5 fetuses were dissected under a microscope and fetuses were genotyped for the $\mathrm{GR}^{\text {null }}$ allele. The pancreas was introduced into a polycarbonate cylinder $(3.35 \mathrm{~mm}$ diameter $\times 1.2 \mathrm{~mm}$ height) to provide a spatial limit to the graft [32] prior to being transplanted under the left kidney capsule of 7-week-old SCID mice previously anaesthetised with Hypnomidate (Janssen-Cilag, Issy-les-Moulineaux, France). One pancreas was implanted per kidney in each SCID mouse. Seven days after the implantation, the SCID mice were injected with 5-bromo-2'-deoxyuridine (BrdU) (50 mg/kg; Sigma, Saint Quentin Fallavier, France) $1 \mathrm{~h}$ before killing, and the grafts were removed. Grafted tissues with part of the adjacent kidney were fixed, sectioned throughout their length and processed for immunohistochemistry as described below.

Immunohistochemistry

Tissue sections were submitted to a 12-min microwave treatment after boiling in citrate buffer (Antigen Retrieval Citra Solution; Biogenex, Alphelys, Plaisir, France), permeabilised for 20 min with $0.1 \%$ Triton X-100 in TBS and incubated 30 min with a blocking buffer $(0.1 \%$ Tween 20 in $3 \%$ BSA in TBS) prior to an overnight incubation with primary antibodies at $4^{\circ} \mathrm{C}$. Secondary antibodies $(1: 200)$ were incubated for $1-4 \mathrm{~h}$ at room temperature. Double immunohistochemistry was performed using fluorescentdye-coupled secondary antibodies visualised under a Leica DMR microscope, or alternatively using enzyme-linked secondary antibodies revealed by diaminobenzidine or Fast Red substrates (Dako, Trappes, France). The antibodies used are described below.

Primary antibodies were: rabbit anti-Pdx-1 [33]; mouse anti-insulin (Sigma); mouse anti-BrdU (Amersham Pharmacia Biotech Europe GmbH, Saclay, France); rabbit anti-glucagon (Diasorin, Stillwater, MN, USA); rabbit anti-amylase (Sigma); rabbit anti-neurogenin 3 (kind gift of M. S. German); guinea-pig anti-insulin (Dako); and rabbit anti-GR (M20; Santa Cruz Biotechnology, TebuBio, Le Perray en Yvelines, France). The rabbit antiserum against exocrine transcription factor Ptfla was raised by Neosystem (Strasbourg, France) against a synthetic amino acid peptide (C-KSFDNIENEPPFEFVS) corresponding to the carboxyl-terminal 16 amino acids of mouse and rat Ptfla. For immunisation the peptide was coupled to keyhole limpet haemocyanin through a cysteine included as the amino terminus of the peptide.

Secondary antibodies were: FITC-labelled anti-guinea-pig; FITC-labelled anti-rabbit; Texas Red-labelled anti-mouse; Texas Red-labelled anti-rabbit; peroxidaseconjugated anti-guinea-pig; biotin-conjugated anti-rabbit (Immunotech-Beckman Coulter, Marseille, France); and peroxidase-conjugated anti-rabbit (Promega, Charbonnieres, France). Biotin-coupled antibodies were revealed using alkaline phosphatase-conjugated streptavidin (BioGenex) or peroxidase-conjugated streptavidin (Amersham Pharmacia Biotech). Peroxidase was detected with diaminobenzidine and alkaline phosphatase with Fast Red substrate.

Detection of apoptosis

Cell death was examined using the terminal transferasemediated X-dUTP nick end labelling (TUNEL) method with an Apoptag Apoptosis Detection Kit (Intergen, MP Biomedicals, Illkirch, France). Apoptotic nuclei were stained in red with Fast Red substrate.

Beta cell fraction measurements

The beta cell fraction (percent beta cells in the pancreas) was measured as the ratio of the insulin-positive cell area to the total tissue area on the entire section. Pancreatic tissue area and insulin-positive cell area were determined by computerassisted measurements using a Leica DMRB microscope equipped with a colour video camera coupled to a Q500IW computer (screen magnification $\times 24$ ), as previously described [27]. Morphometrical analysis was performed on ten transversal and 240- $\mu \mathrm{m}$-spaced sections from wild-type and $\mathrm{GR}^{+/ \text {null }}$ E18 digestive blocks $(n=5)$. Pancreata from wild-type and $\mathrm{GR}^{\text {null/null }}$ fetuses at $\operatorname{E15.5}(n=3)$ and from wild-type and $\mathrm{GR}^{+/ \text {null }}$ adult mice at 3 months of age $(n=4)$ 
were sectioned throughout their length and the morphometrical analysis was performed on seven or eight $150-\mu \mathrm{m}$ spaced sections per pancreas. The pancreatic volume of $\mathrm{GR}^{\text {null/null }}$ and $\mathrm{GR}^{+/+}$E15.5 fetuses was estimated on the sectioned digestive blocks by multiplying the total pancreatic area morphometrically measured on every tenth section, the number of sections and their thickness. The pancreatic volume of three $\mathrm{GR}^{\text {null/null }}$ mutants was expressed as a percentage of the mean control volume $(n=3)$.

Quantification of beta cell proliferation and islet number in the grafts

Dual immunohistochemistry for BrdU and insulin was performed as previously described [29] and proliferation was expressed as the percentage of insulin-positive cells showing a BrdU-positive nucleus. The number of islets composed of at least two insulin-positive cells associated with one glucagon-positive cell was counted on every fifth section of the grafts throughout their length.

\section{Statistical analysis}

All results are expressed as means \pm SEM. The statistical significance of variations for beta cell fraction was tested by a Mann-Whitney non-parametric test. $p$ values $<0.05$ were considered significant.

\section{Results}

As $\mathrm{GR}^{\text {null/null }}$ mice die at birth [24] we studied the pancreas of these mice at embryonic stage E18. The whole digestive tract from $\mathrm{GR}^{\text {null/null }}$ mutants was smaller and had a pale colour, especially the spleen, compared with the $\mathrm{GR}^{+/+}$ littermates (Fig. 1a,b). Although both the head and the tail of the pancreas were present, the volume of the whole pancreas of $\mathrm{GR}^{\text {null/null }}$ mice was $17.3 \pm 3.1 \%$ that of wildtype littermates, a greater decrease than that in the other digestive organs (Fig. 1a,b). Histologically, despite the presence of all pancreatic cell types, both endocrine and exocrine, no organisation into islets or acini was found (Fig. 1c-f). Beside this lack of structural organisation, insulin immunoreactivity was present, although at weaker levels in E18 GR ${ }^{\text {null/null }}$ fetuses, whereas Pdx-1 immunoreactivity was absent, in striking contrast with the exclusive production of this marker in insulin-positive cells in control fetuses (Fig. 1g,h). Finally, TUNEL staining showed that most pancreatic cells, including beta cells, were apoptotic in the mutant fetuses compared with wild-type littermates, suggesting that this tissue was dying (Fig. 1i,j), although all mutant fetuses were alive when taken out from the dams.

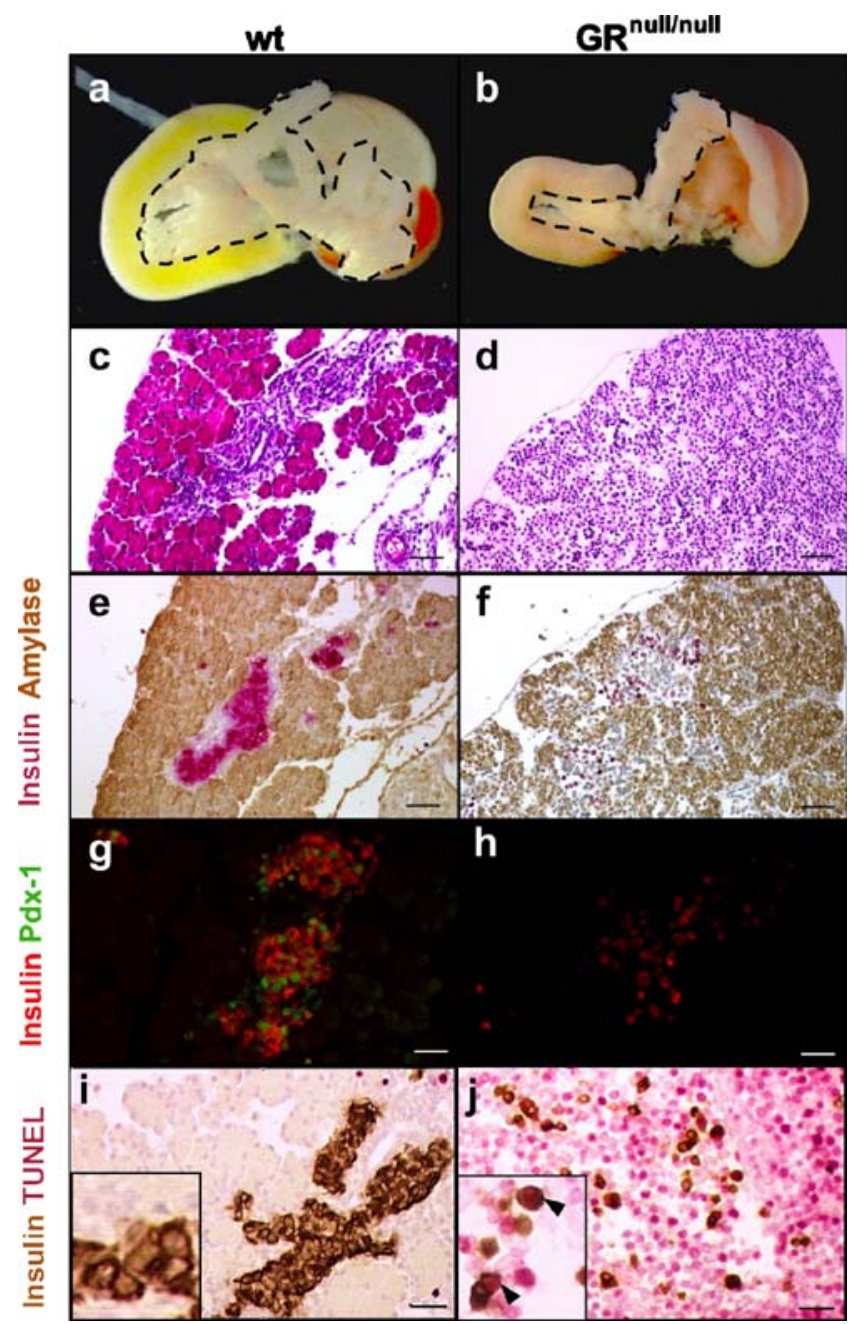

Fig. 1 Dramatic growth failure and organisation of the E18 GR ${ }^{\text {null/null }}$ pancreas. At E18, GR ${ }^{\text {null/null }}$ mutants $(\mathbf{b}, \mathbf{d}, \mathbf{f}, \mathbf{h}, \mathbf{j})$ show a profound growth failure of the whole digestive tract compared with their wildtype (wt) littermates (a, $\mathbf{c}, \mathbf{e}, \mathbf{g}, \mathbf{i})$. The pancreatic volume (dashed line) was even more dramatically reduced than the other digestive organs in the mutant (b). Histological staining (c, d) and double immunohistochemistry for insulin (dark pink) and amylase (brown) (e, f) showed a totally disorganised pancreatic structure with no acini or islets in the null mutant, despite the presence of insulin- or amylase-expressing cells. Insulin-expressing cells from $\mathrm{GR}^{\text {null/null }}$ mutants $(\mathrm{red}, \mathbf{h})$ stained faintly for the hormone and did not express Pdx-1 (h), whereas most insulin-positive cells from wild-type fetuses expressed Pdx-1 (green, g). In the $\mathrm{GR}^{\text {null/null }}$ mutant $(\mathbf{j})$ numerous insulin-expressing cells (brown; arrowheads in inset) as well as acinar cells displayed positive TUNEL staining, but not in the control littermates (i). Scale bars $=50 \mu \mathrm{m}(\mathbf{c}-\mathbf{f})$ and $25 \mu \mathrm{m}(\mathbf{g}-\mathbf{j})$

The beta cell fraction was therefore not measurable at this stage in the $\mathrm{GR}^{\text {null/null }}$ mutants.

To gain further insight into the role of the GR, and in particular to investigate the time when it could affect pancreatic development, we studied E15.5 GR null/null $^{\text {nof }}$ fetuses. The pancreas appeared normal with well-formed acini and abundant clusters of endocrine cells (Fig. 2a,b). The beta cell fraction, representing the ratio of insulin- 


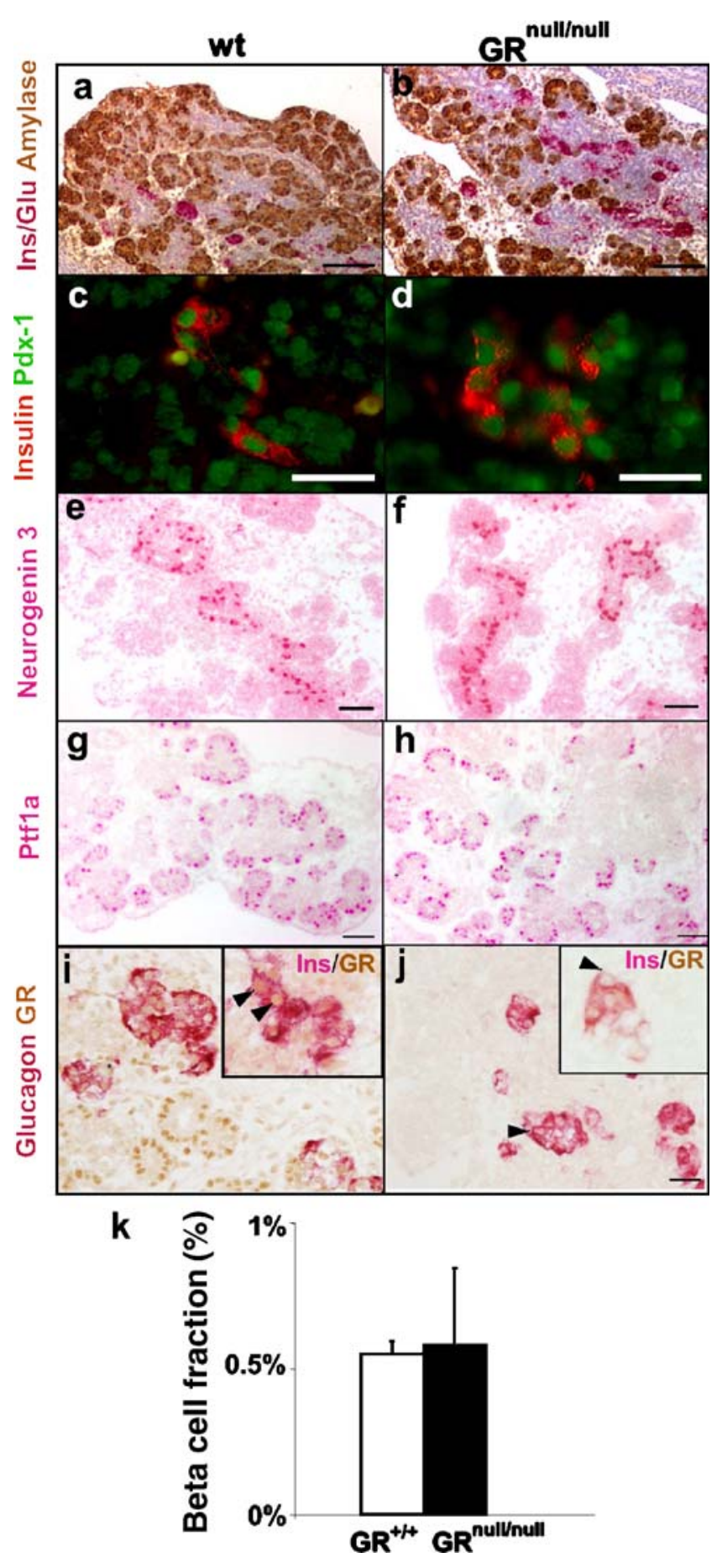

positive area to the total tissue area, was similar in both groups (Fig. 2k). Further characterisation of the pancreatic tissue at E15.5 showed abundant Pdx-1-immunoreactive cells (Fig. 2c,d) in controls and null mutants, few of which were also positive for insulin, a consistent observation for this stage of development. Ptfla-positive cells, as well as endocrine precursor cells immunoreactive for neurogenin 3 were detected similarly in both wild-type and $\mathrm{GR}^{\text {null/null }}$ E15.5 fetuses (Fig. 2e-h). No apoptosis could be observed
Fig. 2 The pancreas is organised normally in $\mathrm{GR}^{\text {null/null }}$ mutants at E15.5. At E15.5, GR ${ }^{\text {null/null }}$ pancreata $(\mathbf{b}, \mathbf{d}, \mathbf{f}, \mathbf{h}, \mathbf{j})$ show well-formed acini (brown) with amylase immunostaining $(\mathbf{a}, \mathbf{b})$ and endocrine cell clusters (dark pink) using a mixture of anti-insulin (Ins) and antiglucagon $(G l u)$ antibodies (a, b), similar to those of their wild-type $(w t)$ littermates. GR ${ }^{\text {null/null }}$ mice show the same differentiation status as their wild-type littermates at E15.5, as shown by the numerous precursor cells expressing Pdx-1 (green fluorescent nuclei, $\mathbf{c}, \mathbf{d}$ ), or the pro-endocrine marker neurogenin 3 (pink nuclei, e, f), and cells expressing the exocrine marker Ptfla (pink nuclei, $\mathbf{g}, \mathbf{h}$ ). At this stage, only few Pdx-1-expressing cells also expressed insulin (red fluorescent staining, c, d). In the $\mathrm{GR}^{\text {null/null }}$ fetuses GR was not expressed in exocrine cells, or in alpha cells (j) or beta cells (inset in $\mathbf{j}$ ), whereas immunopositive nuclei (brown) can be detected in acinar cells as well as in alpha cells and insulin cells (arrowheads, inset in i) in wild-type littermates. Beta-cell fraction analysed as the ratio of insulin-positive area to the total tissue area (k) was indistinguishable in $\mathrm{GR}^{\text {null/null }}$ and wild-type ( $\mathrm{GR}^{+/+}$littermates) fetal pancreata at that stage $(n=3$ animals per group, means $\pm \mathrm{SEM}$ ). Scale bars $=50 \mu \mathrm{m}$, except $\mathbf{c}, \mathbf{d}, 25 \mu \mathrm{m}$

in either control $\left(\mathrm{GR}^{+/+}\right)$or $\mathrm{GR}^{\text {null/null }}$ fetal pancreata (results not shown). At this stage the GR was present in acinar cells, as well as in beta and alpha cells in $\mathrm{GR}^{+/+}$ fetuses (Fig. 2i). Somatostatin and pancreatic polypeptide cells could not be visualised at this early stage. Taken together these results indicate that pancreatic differentiation in $\mathrm{GR}^{\text {null/null }}$ fetuses had proceeded normally until E15.5 despite the absence of the GR (Fig. 2j) and that the glucocorticoid-sensitive period probably lies at a later fetal stage.

To discriminate which elements of the $\mathrm{E} 18 \mathrm{GR}^{\text {null/null }}$ mutant phenotype were due to the absence of GR in the pancreas or the environment, pancreata from $\mathrm{GR}^{\text {null/null }}$ or $\mathrm{GR}^{+/+}$littermates at E15.5 were grafted for 7 days under the renal capsule of SCID mice. A large number of ducts immunoreactive for pan-cytokeratin (Fig. 3a,b) developed in grafted pancreata from both groups. Neurogenin 3positive pro-endocrine cells were no longer detected, either in control or in $\mathrm{GR}^{\text {null/null }}$ grafts (results not shown). Isletlike structures, composed of insulin cells surrounded by glucagon cells, were present in grafted $\mathrm{GR}^{\text {null/null }}$ and control pancreata (Fig. 3c,d). There was a tendency for the number of these islet-like structures to be increased in $\mathrm{GR}^{\text {null/null }}$ grafts $\left(36 \pm 6\right.$ islets vs $16 \pm 8$ in $\left.\mathrm{GR}^{+/+}, p=0.12\right)$, but the difference did not reach statistical significance. Moreover, most of the insulin-positive cells were also positive for Pdx-1 (Fig. 3e,f), proliferated similarly in both types of grafts $\left(17 \pm 8 \%\right.$ in $\mathrm{GR}^{\text {null/null }}$ vs $20 \pm 6 \%$ in $\mathrm{GR}^{+/+}$, Fig. $\left.3 \mathrm{~g}, \mathrm{~h}\right)$ and did not show any apoptosis (results not shown). These results showed that the massive cell death observed at E18 in the $\mathrm{GR}^{\text {null/null }}$ mice was rescued and that the pancreatic islet cells from this fetal tissue had matured and proliferated normally when E15.5 GR ${ }^{\text {null/null }}$ pancreata were grafted in a GR-expressing adult environment. 

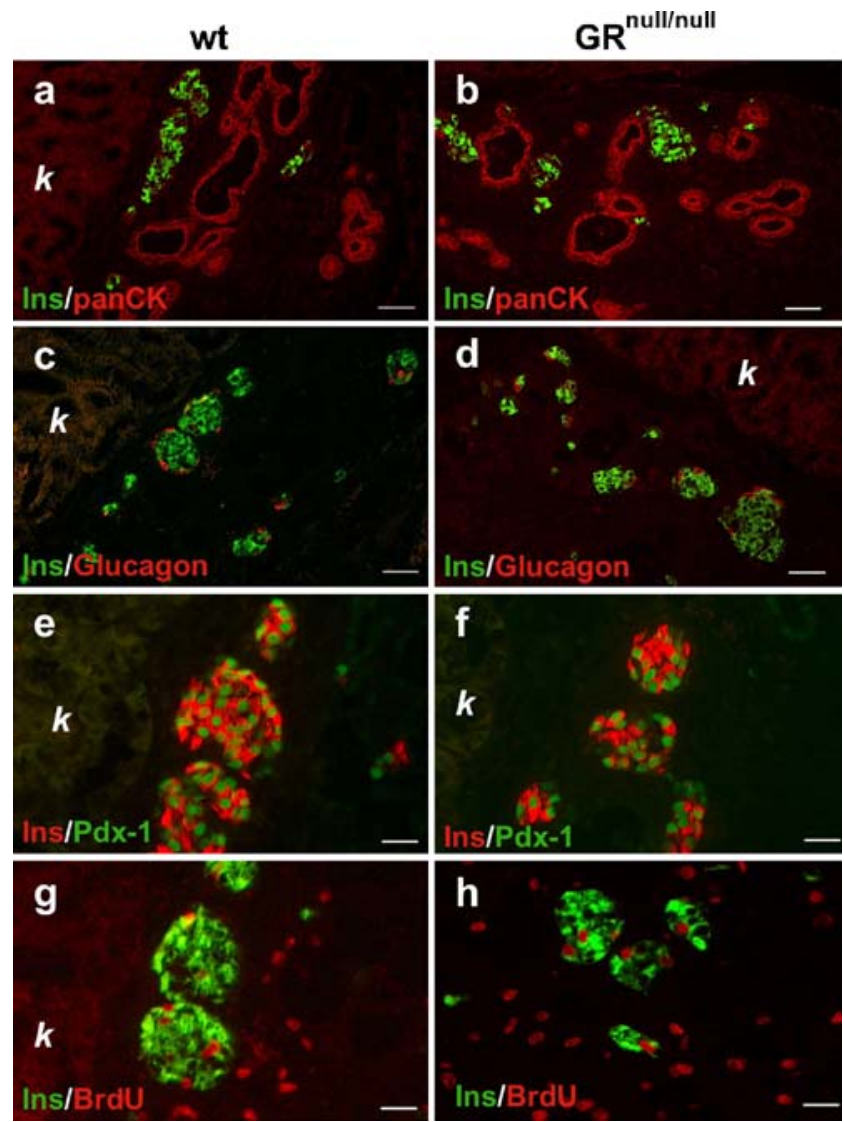

Fig. 3 Rescue of endocrine differentiation upon grafting the $\mathrm{GR}^{\text {null }}$ null pancreas. Three pancreata from $\mathrm{GR}^{\text {null/null }}(\mathbf{b}, \mathbf{d}, \mathbf{f}, \mathbf{h})$ or $\mathrm{GR}^{+/+}$ littermates (a, c, e, g) fetuses at E15.5 were grafted for 7 days under the kidney capsule of SCID mice. One hour before killing, the animals were injected with BrdU, as described in Materials and methods. Both groups of grafted tissue showed indistinguishable immunohistochemical patterns: ducts expressing pan-cytokeratin (panCK) (red, a, b) were intermingled with endocrine cell clusters (green, a, b). Islets were composed of glucagon-expressing cells $(\mathrm{red}, \mathbf{c}, \mathbf{d})$ surrounding a core of insulin (Ins)-positive cells (green, $\mathbf{c}, \mathbf{d})$. All the insulin-positive cells (red, e, f) had matured and expressed Pdx-1 (green nuclei, e, f). Beta-cell proliferation rates analysed by double immunohistochemistry for BrdU (red nuclei) and insulin (green) were identical in both groups of grafted tissue $(\mathbf{g}, \mathbf{h}) . k$, kidney; $w t$, wild-type. Scale bars $=50 \mu \mathrm{m}(\mathbf{a}-\mathbf{d})$ and $25 \mu \mathrm{m}(\mathbf{e}-\mathbf{h})$

To study a possible dosage effect of the GR on pancreatic and islet development we studied heterozygous $\mathrm{GR}^{+/ \text {null }} \mathrm{E} 18$ fetuses and adult mice in which the number of GR is reduced. The overall pancreatic architecture of E18 $\mathrm{GR}^{+/ \text {null }}$ fetuses was similar to that of $\mathrm{GR}^{+/+}$littermates and no apoptosis was observed (results not shown). The beta cell fraction in the pancreas was increased twofold in the heterozygous mutants compared with that of E18 $\mathrm{GR}^{+/+}$ littermates, indicating a negative role for the GR in late beta cell development and expansion (Fig. 4). Interestingly, the increased beta cell fraction persisted in 3-month-old adult heterozygous mice (Fig. 4); however, no difference in glucose tolerance was found in heterozygous animals a

b
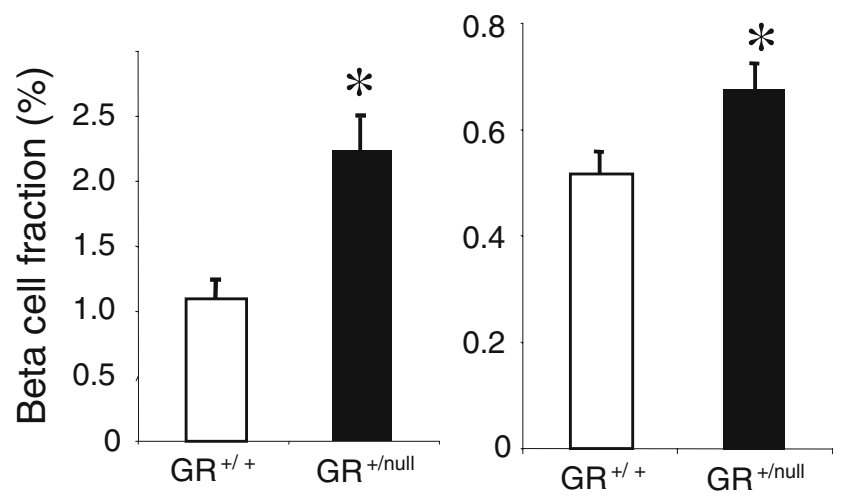

Fig. 4 Reducing GR numbers $\left(\mathrm{GR}^{+/ \text {null }}\right)$ increases the beta cell fraction in E18 and adult pancreata. Beta cell fraction, analysed as the ratio of insulin-positive area to the total tissue area, was increased twofold in $\mathrm{GR}^{+/ \text {null }}$ E18 fetuses (a) and 1.3-fold in $\mathrm{GR}^{+/ \text {null }}$ adults (b) compared with that of wild-type age-matched animals. ${ }^{*} p<0.05$, Mann-Whitney non-parametrical test; $n=5$ and $n=4$ (means \pm SEM) in both groups in E18 fetuses and adult animals, respectively

compared with their wild-type littermates (results not shown).

\section{Discussion}

Several studies have suggested that fetal overexposure to glucocorticoids can alter pancreatic development and thereby programme consequences for glucose homeostasis in the adult $[28,29,34]$. From our previous work investigating the direct effects of glucocorticoids on pancreatic development, by inactivating the GR either in all pancreatic progenitors $\left(\mathrm{GR}^{\mathrm{Pdx}-\mathrm{Cre}}\right.$ mice) or specifically in insulin-producing cells ( $\mathrm{GR}^{\mathrm{RIP}-\mathrm{Cre}}$ mice), we concluded that the GR is not necessary for beta cell development but rather prevents it through a direct effect on pancreatic progenitors [29]. By studying mice deleted for GR in the whole organism $\left(\mathrm{GR}^{\text {null/null }}\right.$ mice), we show here that GR is not required for the early induction of pancreatic development and differentiation but is nevertheless necessary in the pancreatic environment, and thereby through indirect effects, for pancreatic morphogenesis during late fetal development. Moreover, heterozygous mutants with reduced GR showed an increased beta cell fraction, further documenting the negative role of glucocorticoids on beta cell development and strengthening the importance of a precise GR dosage to control beta cell mass expansion.

First, we showed that pancreatic development proceeds normally until E15.5 in the $\mathrm{GR}^{\text {null/null }}$ mutant. The tissue structure was similar in mutant and wild-type mice, showing exocrine cells organised into acini and insulin and glucagon cells grouped into small endocrine clusters. 
Second, all cell populations existing in wild-type fetuses were also present in mutants: precursor cells immunoreactive for Pdx-1 but not insulin, endocrine precursor cells positive for neurogenin 3 , together with already differentiated exocrine cells positive for Ptfla and amylase, or endocrine cells producing insulin. Finally, morphometrical measurements showed that the beta cell fraction was identical between wild-type and $\mathrm{GR}^{\text {null/null }}$ fetuses. Taken together, these results show that GR is not necessary either for the first steps of pancreatic development taking place before E15.5, including pancreatic patterning of the endoderm, budding and ramification, or for the expansion of the beta cell mass until this stage. Indeed, profound defects were seen in E18 GR ${ }^{\text {null/null }}$ fetuses, among which was a general reduction in the size of all organs comprising the digestive tract, associated with a massive apoptotic rate. However, even though there seems to be a general death process, the pancreas was much more altered than the other organs, as its volume represented only $17 \%$ of that of an age-matched wild-type pancreas. The exponential pancreatic growth during the last days of pregnancy is a probable explanation for these defects being more acute in the pancreas than in other organs. The explanation for the large number of apoptotic cells in the GR ${ }^{\text {null/null }}$ pancreas at E18 remains unclear: it could be either the cause or the consequence of the lack of structure observed. However, glucocorticoid levels have already been reported to play a role in the apoptotic process of various endodermally derived cell types. More precisely, it has been shown that dexamethasone treatment leads to an increased production of the anti-apoptotic factors Bcl2, BclxL or cFLIP (an inhibitor of caspase-8) in human and rat hepatocytes [35], or c-IAP2 (cellular inhibitor of apoptosis 2) in human lung epithelial cells [36]. Moreover, Wistar Bonn/Kobori rats, which spontaneously develop chronic pancreatitis, have a decreased pancreatic weight, low endogenous corticosterone levels and increased acinar cell apoptosis [37]. In this rat model, acinar cell apoptosis can be attenuated by prednisolone treatment, strengthening the role of glucocorticoids in maintaining a low apoptotic rate in the pancreas, possibly by decreasing inflammation.

Taken together, these studies show an anti-apoptotic role of glucocorticoids consistent with the spectacularly increased apoptotic rate observed in the whole digestive tract of GR-deficient mice. As pancreatic apoptosis was rescued in $\mathrm{E} 18 \mathrm{GR}^{+/ \text {null }}$ heterozygous mutants, we have demonstrated that low levels of GR are sufficient to prevent pancreatic cell death.

The graft experiments allowed us to discriminate which elements of the $\mathrm{E} 18 \mathrm{GR}^{\text {null/null }}$ pancreatic phenotype were due to the absence of glucocorticoid signalling in the pancreas or the environment, i.e. discriminate between direct and indirect effects. The grafted tissue demonstrated normal organisation and fully differentiated endocrine cells in islets, with Pdx-1 immunoreactivity restricted to insulinpositive cells and the disappearance of neurogenin 3-positive cells. The increased apoptosis observed in E18 $\mathrm{GR}^{\text {null/null }}$ fetuses was rescued upon grafting E15.5 mutant pancreata into SCID mice, a GR-expressing environment, thus demonstrating that $\mathrm{GR}^{\text {null/null }}$ pancreatic cell death can be attributed to indirect effects of glucocorticoids on this tissue. This situation, where GR is absent only in the pancreas, resembles that of $\mathrm{GR}^{\text {Pdx-Cre }}$ mice showing no defects in pancreatic tissue structure [29], strengthening the importance of a GR-expressing environment to preserve pancreatic structure. These results also allow us to define a critical developmental period, after E15.5 and probably before E18, when pancreatic viability is particularly dependent on GR function in the environment. Interestingly, this time period coincides with high GR expression in the pancreas, as well as several other organs such as the liver, intestine, kidney and placenta [4], suggesting that these organs, sensitive to glucocorticoids, could relay the indirect effects of glucocorticoids on the pancreas. The mechanisms underlying this massive cell death are far from being deciphered and would require thorough investigations of multiple fields. Nevertheless, several mechanisms can be proposed. First, these mutants show defective erythropoiesis $[6,24]$, a defect which could contribute to the massive cell death. Second, another plausible cause, in line with the pale colour of the spleen and of all organs composing the digestive tract, could be impaired vascularisation. However, pancreatic platelet/endothelial cell adhesion molecule-1 staining did not show any obvious abnormalities (results not shown). Third, the absence of GR could involve the lack of glucocorticoid-dependent production by other organs of factors favouring pancreatic survival. Alternatively, GR deficiency may also induce the production of pro-apoptotic factors by the environment.

As well as these indirect effects on pancreatic survival, glucocorticoids also have direct effects on beta cell expansion. Our previous experiments inactivating the GR in the pancreatic progenitors $\left(\mathrm{GR}^{\text {Pdx-Cre }}\right.$ mice) showed that the GR was not necessary for pancreatic morphogenesis and its absence rather increased beta cell mass [29]. Interestingly, our observations in heterozygous $\mathrm{GR}^{+/ \text {null }}$ mutants, with reduced GR in the whole organism, similarly show a markedly increased beta cell fraction at E18 that persisted in adults. In line with this finding, we also observed slightly increased islet numbers in the grafts originating from $\mathrm{GR}^{\text {null/null }}$ fetuses compared with those from control fetuses, but the small numbers of grafts did not allow us to show any significant difference. This pancreatic phenotype, also similar to that of $\mathrm{GR}^{\text {Pdx-Cre }}$ mice [29], confirms our earlier finding regarding a direct action of the GR signalling pathway on beta cell expansion, but more 
importantly strengthens the idea of an accurate GR dosage on the control of this expansion. This suggests that any changes leading to modifications of the glucocorticoid signalling pathway (GR protein level and affinity, glucocorticoid circulating levels, cofactor availability) could affect beta cell mass when fluctuating within a physiological range. The observation that the heterozygous mutation of the gene encoding GR led to a strong pancreatic phenotype suggests that natural variations in GR expression could have similar consequences in humans. It would therefore be of the greatest interest to look at polymorphisms of the gene encoding GR in both normal and diabetic populations, as well as in non-diabetic obese adults, in whom the beta cell mass has been suggested as being protective against diabetes [38].

To summarise, we have shown that the glucocorticoid signalling pathway is not required for early steps of pancreatic development before E15.5. Indeed, we define a critical period in late fetal life when glucocorticoid signalling is necessary both to maintain pancreatic survival through indirect effects and to control beta cell mass through direct effects. Moreover, these two different effects are sensitive to different levels of activation of the GR. In the context of fetal programming of the metabolic syndrome by glucocorticoids, preventing glucocorticoid overexposure is thereby not sufficient; it is necessary to focus on how to maintain glucocorticoid signalling in a defined range of activation.

Acknowledgements This work was supported by Institut National de la Santé et de la Recherche Médicale and the Centre National de la Recherche Scientifique, as well as by the European Union (FP6 Earnest program Food-CT-2005-007036) and the Agence Nationale de la Recherche (ANR grant No. A05245DS) to B. Breant and F. Tronche and by the Juvenile Diabetes Research Foundation (JDRF Centre for B-cell therapy in Europe) to R. Scharfmann. The authors wish to thank Dr A. Grapin-Botton and Pr P. Ferré for critical reading of the manuscript. We are grateful to Dr M. S. German (UCSF, San Francisco, CA, USA) for providing us with the anti-neurogenin 3 antibodies. E. Gesina and A. Milet were doctoral recipients of Ministère de l'Education Nationale, de la Recherche et de la Technologie.

Duality of interest This work involved no duality of interest.

\section{References}

1. Sapolsky RM, Romero LM, Munck AU (2000) How do glucocorticoids influence stress responses? Integrating permissive, suppressive, stimulatory, and preparative actions. Endocr Rev 21:55-89

2. de Kloet ER (2003) Hormones, brain and stress. Endocr Regul 37:51-68

3. Sandeep TC, Walker BR (2001) Pathophysiology of modulation of local glucocorticoid levels by 11 beta-hydroxysteroid dehydrogenases. Trends Endocrinol Metab 12:446-453
4. Speirs HJ, Seckl JR, Brown RW (2004) Ontogeny of glucocorticoid receptor and 11beta-hydroxysteroid dehydrogenase type-1 gene expression identifies potential critical periods of glucocorticoid susceptibility during development. J Endocrinol 181:105-116

5. Kitraki E, Kittas C, Stylianopoulou F (1997) Glucocorticoid receptor gene expression during rat embryogenesis. An in situ hybridization study. Differentiation 62:21-31

6. Tronche F, Kellendonk C, Reichardt HM, Schutz G (1998) Genetic dissection of glucocorticoid receptor function in mice. Curr Opin Genet Dev 8:532-538

7. Valdez R, Athens MA, Thompson GH, Bradshaw BS, Stern MP (1994) Birthweight and adult health outcomes in a biethnic population in the USA. Diabetologia 37:624-631

8. Lithell HO, McKeigue PM, Berglund L, Mohsen R, Lithell UB, Leon DA (1996) Relation of size at birth to non-insulin dependent diabetes and insulin concentrations in men aged 50-60 years. Br Med J 312:406-410

9. Barker DJ, Hales CN, Fall CH, Osmond C, Phipps K, Clark PM (1993) Type 2 (non-insulin-dependent) diabetes mellitus, hypertension and hyperlipidaemia (syndrome $\mathrm{X}$ ): relation to reduced fetal growth. Diabetologia 36:62-67

10. Hales CN, Barker DJ, Clark PM et al (1991) Fetal and infant growth and impaired glucose tolerance at age 64 [see comments]. Br Med J 303:1019-1022

11. Aron DC, Schnall AM, Sheeler LR (1990) Spontaneous resolution of Cushing's syndrome after pregnancy. Am J Obstet Gynecol 162:472-474

12. Reinisch JM, Simon NG, Karow WG, Gandelman R (1978) Prenatal exposure to prednisone in humans and animals retards intrauterine growth. Science 202:436-438

13. Lindsay RS, Lindsay RM, Waddell BJ, Seckl JR (1996) Prenatal glucocorticoid exposure leads to offspring hyperglycaemia in the rat: studies with the 11 beta-hydroxysteroid dehydrogenase inhibitor carbenoxolone. Diabetologia 39:1299-1305

14. Nyirenda MJ, Lindsay RS, Kenyon CJ, Burchell A, Seckl JR (1998) Glucocorticoid exposure in late gestation permanently programs rat hepatic phosphoenolpyruvate carboxykinase and glucocorticoid receptor expression and causes glucose intolerance in adult offspring. J Clin Invest 101:2174-2181

15. Nyirenda MJ, Seckl JR (1998) Intrauterine events and the programming of adulthood disease: the role of fetal glucocorticoid exposure (Review). Int J Mol Med 2:607-614

16. Langley-Evans SC (1997) Intrauterine programming of hypertension by glucocorticoids. Life Sci 60:1213-1221

17. Langley-Evans SC (1997) Maternal carbenoxolone treatment lowers birthweight and induces hypertension in the offspring of rats fed a protein-replete diet. Clin Sci (Lond) 93:423-429

18. Gremlich S, Roduit R, Thorens B (1997) Dexamethasone induces posttranslational degradation of GLUT2 and inhibition of insulin secretion in isolated pancreatic beta cells. Comparison with the effects of fatty acids. J Biol Chem 272:3216-3222

19. Davani B, Khan A, Hult M et al (2000) Type 111 beta-hydroxysteroid dehydrogenase mediates glucocorticoid activation and insulin release in pancreatic islets. J Biol Chem 275:34841-34844

20. Lambillotte C, Gilon P, Henquin JC (1997) Direct glucocorticoid inhibition of insulin secretion. An in vitro study of dexamethasone effects in mouse islets. J Clin Invest 99:414-423

21. Davani B, Portwood N, Bryzgalova G et al (2004) Aged transgenic mice with increased glucocorticoid sensitivity in pancreatic beta-cells develop diabetes. Diabetes 53(Suppl 1):S51-S59

22. Delaunay F, Khan A, Cintra A et al (1997) Pancreatic beta cells are important targets for the diabetogenic effects of glucocorticoids. J Clin Invest 100:2094-2098

23. Cole TJ, Blendy JA, Monaghan AP et al (1995) Targeted disruption of the glucocorticoid receptor gene blocks adrenergic 
chromaffin cell development and severely retards lung maturation. Genes Dev 9:1608-1621

24. Bauer A, Tronche F, Wessely O et al (1999) The glucocorticoid receptor is required for stress erythropoiesis. Genes Dev 13:2996-3002

25. Finotto S, Krieglstein K, Schober A et al (1999) Analysis of mice carrying targeted mutations of the glucocorticoid receptor gene argues against an essential role of glucocorticoid signalling for generating adrenal chromaffin cells. Development 126:2935-2944

26. Garofano A, Czernichow P, Breant B (1997) In utero undernutrition impairs rat beta-cell development. Diabetologia 40:1231-1234

27. Garofano A, Czernichow P, Breant B (1998) Beta-cell mass and proliferation following late fetal and early postnatal malnutrition in the rat. Diabetologia 41:1114-1120

28. Blondeau B, Lesage J, Czernichow P, Dupouy JP, Breant B (2001) Glucocorticoids impair fetal beta-cell development in rats. Am J Physiol Endocrinol Metab 281:E592-E599

29. Gesina E, Tronche F, Herrera P et al (2004) Dissecting the role of glucocorticoids on pancreas development. Diabetes 53:2322-2329

30. Tronche F, Kellendonk C, Kretz O et al (1999) Disruption of the glucocorticoid receptor gene in the nervous system results in reduced anxiety. Nat Genet 23:99-103

31. Castaing M, Peault B, Basmaciogullari A, Casal I, Czernichow P, Scharfmann R (2001) Blood glucose normalization upon transplantation of human embryonic pancreas into beta-cell-deficient SCID mice. Diabetologia 44:2066-2076
32. Thomas M, Northrup SR, Hornsby PJ (1997) Adrenocortical tissue formed by transplantation of normal clones of bovine adrenocortical cells in SCID mice replaces the essential functions of the animals' adrenal glands. Nat Med 3:978-983

33. Duvillie B, Attali M, Aiello V, Quemeneur E, Scharfmann R (2003) Label-retaining cells in the rat pancreas: location and differentiation potential in vitro. Diabetes 52:2035-2042

34. Shen CN, Seckl JR, Slack JM, Tosh D (2003) Glucocorticoids suppress beta-cell development and induce hepatic metaplasia in embryonic pancreas. Biochem J 375:41-50

35. Bailly-Maitre B, de Sousa G, Zucchini N, Gugenheim J, Boulukos KE, Rahmani R (2002) Spontaneous apoptosis in primary cultures of human and rat hepatocytes: molecular mechanisms and regulation by dexamethasone. Cell Death Differ 9:945-955

36. Webster JC, Huber RM, Hanson RL et al (2002) Dexamethasone and tumor necrosis factor-alpha act together to induce the cellular inhibitor of apoptosis-2 gene and prevent apoptosis in a variety of cell types. Endocrinology 143:3866-3874

37. Hashimoto T, Yamada T, Yokoi T et al (2000) Apoptosis of acinar cells is involved in chronic pancreatitis in $\mathrm{Wbn} / \mathrm{Kob}$ rats: role of glucocorticoids. Pancreas 21:296-304

38. Butler AE, Janson J, Bonner-Weir S, Ritzel R, Rizza RA, Butler PC (2003) Beta-cell deficit and increased beta-cell apoptosis in humans with type 2 diabetes. Diabetes 52:102-110 